\title{
ZBTB16-RARA Fusion Protein Expression
}

National Cancer Institute

\section{Source}

National Cancer Institute. ZBTB16-RARA Fusion Protein Expression. NCI Thesaurus.

Code C37220.

A fusion protein encoded by a $\mathrm{t}(15 ; 17)$ translocation, which involves the human genes

ZBTB16 and RARA and is characteristic of acute promyelocytic leukemia. It is a transcriptional repressor with both gain-of-function and dominant-negative properties, resulting in transcriptional repression of retinoic acid and non-retinoic acid target genes and culminating in differentiation arrest. 